\title{
(6) OPEN ACCESS \\ The patient handover as an entrustable professional activity: adding meaning in teaching and practice
}

${ }^{1}$ Center for Research and Development of Education, University Medical Center Utrecht, Utrecht,

The Netherlands

${ }^{2}$ Department of Medicine, University of California, San Francisco, California, USA

${ }^{3}$ Department of Psychiatry, University of California, San Francisco, California, USA

${ }^{4}$ Department of Psychiatry, Kaiser Permanente Oakland Medical Center, Oakland, California, USA

Correspondence to Dr ThJ (Olle) ten Cate, Center for Research and Development of Education, University Medical Center Utrecht, P.0. Box \# 85500, 3508 GA Utrecht,

The Netherlands; t.j.tencate@umcutrecht.nl

Accepted 26 September 2012

Olle ten Cate, ${ }^{1,2}$ John $Q$ Young ${ }^{3,4}$

Major healthcare reform, including limits on work hours for health professionals and the involvement of multiple individuals, teams and settings have made handovers a common and frequent aspect of patient care. Research has shown that errors commonly occur during handovers, and can result in patient harm. ${ }^{12}$ As a result, healthcare systems, at the behest of regulatory agencies, must now ensure that handover processes are safe and reliable. Similarly, medical education programmes and credentialing bodies are required to monitor clinician competence with respect to handovers.

Developing valid measures of clinician competence is a major challenge. The handover requires the application and integration of clinical and communication skills, and an understanding of the systems of care, which must come together in one, time-limited and highly constrained activity. ${ }^{3}{ }^{4}$ Acquiring the ability to perform this activity well is, because of its complexity, not a simple linear process and requires years to perfect. A trainee cannot be asked to study it from a book, or practice in a course, with the expectation of a satisfactory score on a skills assessment. The quality of handing over patient information and responsibility is highly provider and contextdependent and case-specific. Because many doctors do it on a daily basis, it must be learned in training and the competence to do this should be assessed. Well trained physicians should be trusted to provide adequate information in handovers, and recipient doctors and other healthcare professionals must understand, accept and appropriately apply this information to guarantee optimal care.

Policy makers and educators have called for added training of healthcare professionals to improve their skills and competence for conducting handovers. The European HANDOVER Project encompassed several initiatives to improve the education and training of healthcare professionals in this important area of patient safety and continuity of care.$^{5-7}$ While the need for added training in handovers is gaining wider acceptance, assessment of the effects of education on the ability to provide safe and effective handovers has lagged behind. Regular in-training assessment methods in medical education do not focus on circumscribed activities as units of evaluation. Rather, competency-frameworks, such as the Canadian CanMEDS model or the US ACGME model focus on the myriad component skills, knowledge and attitudes necessary to perform the duties of a physician, with assessment of knowledge still being the most common method. Yet the core clinical activities of a physician are holistic in nature, that is, represent the simultaneous application and integration of many competencies, in a dynamic and fluid context. As a framework for assessment, it is questionable whether the deconstructed approach of assessing separate competencies can justify decisions to entrust a trainee, or for that matter, any clinician with the responsibility to carry out clinical activities. $^{8}$

To link competency-frameworks to actual practice for the purpose of training and assessment, the concept of 'Entrustable Professional Activities' (EPAs) was designed. ${ }^{9}{ }^{10}$ EPAs are units of professional practice, defined as tasks or responsibilities to be entrusted to a trainee once sufficient specific competence is reached to allow for unsupervised practice. EPAs are independently executable within a time frame and observable and measurable in their process and outcome, and, therefore, suitable for entrustment decisions. Typically, EPAs can be scheduled and allocated to individuals. It is also clear that entrustment decisions are highly contextual and vary, among other attributes, by time of day, adjacent personnel, geographic location of the supervisor 
relative to the trainee, and other team and systems factors. ${ }^{11}$ As a sign of progressive independence of the trainee, the level of mastery of an EPA is reflected by five stages of decreasing supervision ${ }^{10}{ }^{12}$ : (1) no task execution, (2) task execution under direct supervision on site, (3) task execution with supervision quickly available on call, (4) unsupervised practice and (5) supervision may be provided to juniors. Level 4 reflects formal entrustment. 'Unsupervised' does not exclude supervision at a distance, which must be present throughout residency, but checking can be done post hoc or virtually. ${ }^{13}$ The ultimate aim of the application of EPAs is not to result in 'independent practice' in any literal sense, as healthcare is becoming increasingly interdependent, and collaboration is the standard rather that the exception. Rather 'independent practice' refers to when clinicians have demonstrated the ability and judgment to take full, proactive responsibility for their role, based on a genuine professional contribution to the healthcare team, and therefore no longer require supervision by a teacher or proctor to certify the quality or safety of their work.

The full description of an EPA can be structured in eight paragraphs with an intended length of not more than two pages. In this contribution we have attempted to provide a full description of the patient handover as an EPA. As EPAs primarily have an educational purpose, that is to facilitate competency-based medical education, the physician is called 'trainee'. However, this framework is equally relevant to any kind of process of certification or credentialing and could also be applied to nonphysician handover training.

\section{DISCUSSION}

An EPA description for patient handover provides a tool to plan, educate and assess clinicians in any training setting, while complying with all requirements of a competency-based programme. ${ }^{20}$ The EPA is explicitly linked to the competency framework and allows programmes to monitor progress and milestones in trainees, allowing them to consider tailoring the length of training to the competence attained at the level of the individual. ${ }^{21}$ Once the threshold of competence for unsupervised practice is reached, a justified entrustment decision can be made and documented and the individual can move to the level of supervision at a distance. ${ }^{13}$ The decision to trust a medical trainee, or a healthcare worker in general, to perform unsupervised critical EPA can be considered a significant milestone towards certification and licensing. If executed and documented well, entrustment decisions do not only bear responsibility upon those who become acknowledged, but also upon those who make the entrustment decisions. To the medical community and the public, EPAs can serve to offer transparency in what trainees and certified healthcare workers can and cannot do safely. EPAs may be added after a formal training period, be part of a structured continuing medical education programme and should hold as long as the practitioner maintains his or her EPA-related competence. EPAs are not confined to physicians. Similar EPAs may also become the units for training, assessment and certification of physician assistants, nurse practitioners and others. ${ }^{12}$ In this respect, EPAs focus on patient care tasks rather than on traditional professions and disciplines.

This example of an EPA can be adjusted to local needs but provides a framework for training, and can also serve as an example for other EPA descriptions. The description provides a language to stimulate agreement on a standard and grounding upon which to build a minicurriculum. This standard can be further detailed in two respects. One is to elaborate the section link with an existing competency framework. This link provides credibility and a framework for observation and assessment. Clearly, communication, collaboration, health advocacy and medical expertise frame any observational instruments used for handovers. Englander has shown that developmental milestones on handovers can be added to this framework. For example, advanced beginners may use a standard template for handovers, whereas an expert 'adapts and applies the template without error and regardless of setting or complexity'. ${ }^{22}$ Next, the criteria for entrustment decisions can be elaborated. We have recommended 10 proficient handovers without errors by at least two different evaluators as the threshold based on what research has suggested is a valid sample for competency judgments. However, this standard can vary, should be customised to the trainee and the EPA complexity and needs to be substantiated further. ${ }^{23}$

Future research should focus on identifying the objective markers or milestones associated with each level of mastery and supervision. A number of characteristics of handovers that correlate with quality of subsequent care have been reported, but few show generalised effects across settings. ${ }^{24}{ }^{25}$ Future studies should further inform the criteria to trust trainees handing over patients.

Handovers require the integration of clinical, communication and systems skills, irrespective of whether the health professionals involved are physicians, nurses or other clinicians. While we have used primarily graduate medical education as the setting for our working example, the EPA framework could be used across the range of clinical and allied healthcare professions to establish when clinicians need proctoring, closer monitoring and/or supplemental training. If close supervision only stops when the clinician has demonstrated the ability to effectively perform handoffs, 


Title Patient handover

Justification

Description

Link with a competency framework

Required knowledge, skills and attitudes
As the healthcare system has increased in complexity, we have seen a commensurate increase in the number of handovers both within settings (eg, shift $A$ to shift $B$, team $A$ to team B, hospital ER-to-floor, floor-to-ICU,) and between settings (eg, home-to-hospital and hospital-to-rehabilitation facility-to-outpatient clinic). At the same time, continuity of healthcare providers has decreased, resulting in transitions of care being more vulnerable to error. This EPA is critical to our ability to sustain and improve patient safety. Handing over the responsibility for a patient and the related patient information requires a core capacity that every physician should have.

The EPA Patient Handover includes (a) the provision of information about patients to another healthcare provider and (b) the reception of information about patients from another healthcare provider, always in conjunction with the transfer of direct responsibility for this patient's care, in full or in part. The EPA includes all handovers within institutions or settings (such as Emergency room-to-floor, floor-to-Intensive care unit, Operation room-to-floor, shift A to shift B, team A to team B) and across institutions or settings (such as hospital-to-home, hospital-to-rehabilitation setting). It does not include information provision between healthcare providers if the primary responsibility is not handed over.

The EPA Patient Handover also includes both oral information transfer and written information transfer (such as through the electronic medical record).

The information that is transferred includes at least patient demographics, a concise medical history, current problems and issues, pending lab/radiographic and other diagnostic results information, anticipatory guidance/upcoming possibilities, and a justified to-do list. ${ }^{14}$

The EPA applies to all clinical disciplines and settings, but can be restricted in content for any discipline. Entrustment decisions to practice unsupervised must include such restrictions.

Most relevant domains of competence from the competency-framework of the Accreditation Council for Graduate Medical Education: Patient Care, Interpersonal and Communication Skills, Practice-based Learning and Improvement, ${ }^{15}$ or from the CanMEDS framework: Communicator, collaborator, Health Advocate, Medical Expert. ${ }^{16}$

\section{Knowledge}

The trainee must have satisfactory medical knowledge to fully understand all details of the condition of the patient, including diseases present and their potential future complications, anticipate future developments, and prioritise competing tasks. Knowledge of all common illness scripts of the discipline and setting is required, if the trainee is to be entrusted with the responsibility to conduct handovers in this discipline and setting.

Skills

Communication skills pertain to communication with clinicians, with family or with other caregivers. These skills must include communicating situation awareness, illness severity, action and contingency plans to other healthcare providers, preferably using a standardised verbal and written template to improve reliability of the information transfer and prevent errors of omission. The trainee as a healthcare professional accepting responsibility for the patient also has specific communication skills, including clarifying and synthesising information, making sure that the received mental model matches the sender's mental model, and providing feedback to the individual instigating the handover on any errors that occurred, including inaccurate information transmission.

Attitude

To allow for an entrustment decision for unsupervised practice, the trainee must show willingness to take sufficient time for information transfer, to understand the perspective of the counterpart, especially if not from the same profession, and to serve the patients' interest above institutional and specialty interests.

Teaching approaches

Trainees must learn to systematically structure oral handovers, for example, using a mnemonic such as Situation, Background, Assessment Recommendation ${ }^{17}$ or the newer IPASS (IIIness severity, Patient summary, Action list, Situation awareness and Contingency planning, Synthesis by the receiver ${ }^{18}$ ) and the electronic medical record as a dynamic tool. A number of focused interactive workshop sessions practicing handovers are recommended. 
Continued

\begin{tabular}{ll}
\hline Title & Patient handover \\
\hline $\begin{array}{l}\text { Sources of information to } \\
\text { evaluate progress }\end{array}$ & $\begin{array}{l}\text { Structured observations during handovers, using an observation and feedback tool, } \\
\text { preferably validated }\end{array}$ \\
& $\begin{array}{l}\text { Structured assessment of written or electronic transfer information } \\
\text { Anticipatory guidance-'what if' discussion with the trainee to explore ability to cope with } \\
\text { challenging case situations }\end{array}$ \\
Estimated stage of training & $\begin{array}{l}\text { End of first year of residency training (supervision at a distance is to be present throughout } \\
\text { residency) } \\
\text { practice) is to be reached } \\
\text { Basis for formal entrustment } \\
\text { decisions }\end{array}$ \\
& $\begin{array}{l}\text { At least two supervisors/attendings physicians must have observed at least 10 consecutive } \\
\text { oral handovers with a variety of patients and situations, with the trainee in the provider role, } \\
\text { and 10 with the trainee in the recipient role, all conducted proficiently and without errors or } \\
\text { omissions. } \\
\text { At least two supervisors/attending physicians must have evaluated handover information of } \\
10 \text { consecutive patients, with a variety of patients and situations, all judged as being } \\
\text { proficient. }\end{array}$ \\
\hline
\end{tabular}

essential clinical information will be omitted less frequently and a shared mental model for what needs to happen with the patient will more commonly be established. This will mean fewer communication errors and less harm to patients. The EPA framework will enhance patient safety by providing a reliable and valid approach to determining the level of supervision any clinician requires to effectively perform a handover.

Acknowledgements The authors thank Drs Carol Carraccio and Robert Englander for their Handover EPA text designed for paediatric residency, parts of which have been used in our description, and for their comments on an earlier version of this manuscript. And they wish to thank the editors of BMJ Quality and Safety with their help to optimise the manuscript.

Contributors The authors collaboratively conceived of and wrote the paper.TJ OC drafted its first version and JQY added with critical adjustments and additions.

Competing interests None.

Provenance and peer review Not commissioned; externally peer reviewed.

Data sharing statement This viewpoint paper does not use empirical data.

Open Access This is an Open Access article distributed in accordance with the Creative Commons Attribution Non Commercial (CC BY-NC 3.0) license, which permits others to distribute, remix, adapt, build upon this work noncommercially, and license their derivative works on different terms, provided the original work is properly cited and the use is non-commercial. See: http:// creativecommons.org/licenses/by-nc/3.0/

\section{REFERENCES}

1. Arora VM, Manjarrez E, Dressler DD, et al. Hospitalist handoffs: a systematic review and task force recommendations. J Hosp Med 2009;4:433-40.

2. Young JQ, Wachter RM. Academic year-end transfers of outpatients. JAMA 2009;302:1327-9.

3. Wohlauer MV, Arora VM, Horwitz LI, et al. The patient handoff: a comprehensive curricular blueprint for resident education to improve continuity of care. Acad Med 2012;87:411-18.

4. Young JQ, Niehaus B, Lieu SC, et al. Improving resident education and patient safety: a method to balance initial caseloads at academic year-end transfer. Acad Med 2010;85:1418-24.

5. Kicken W, Van der Klink M, Barach P, et al. Handover training: Does one size fit all? The merits of mass customization. BMJ Qual Saf 2012.

6. Drachsler H, Kicken W, Van der Klink M, et al. Development of a Patient HANDOVER Toolbox. BMJ Qual Saf 2012.
7. Stoyanov S, Boshuizen H, Groene O, et al. Mapping clinical handover educational interventions. BMJ Qual Saf 2012.

8. Lurie SJ, Mooney CJ, Lyness JM. Measurement of the general competencies of the accreditation council for graduate medical education: a systematic review. Acad Med (Internet) 2009;84:301-9.

9. Ten Cate O. Entrustability of professional activities and competency-based training. Med Educ 2005;39:1176-7.

10. Ten Cate O, Scheele F. Competency-based postgraduate training: can we bridge the gap between theory and clinical practice? Acad Med 2007;82:542-7.

11. Sterkenburg A, Barach P, Kalkman C, et al. When do supervising physicians decide to entrust residents with unsupervised tasks? Acad Med 2010;85:1408-17.

12. Mulder H, Ten Cate O, Daalder R, et al. Building a competency-based workplace curriculum around entrustable professional activities: the case of physician assistant training. Med Teach 2010;32:e453-9.

13. Babbott S. Commentary: watching closely at a distance: key tensions in supervising resident physicians. Acad Med 2010;85:1399-400.

14. Derienzo CM, Frush K, Barfield ME, et al. Handoffs in the era of duty hours reform: a focused review and strategy to address changes in the accreditation council for graduate medical education common program requirements. Acad Med 2012;87:403-10.

15. Batalden P, Leach D, Swing S, et al. General competencies and accreditation in graduate medical education. Health Aff 2002;21:103-11.

16. CanMEDS. CanMEDS 2000: Extract from the CanMEDS 2000 Project Societal Needs Working Group Report. 2000;22:549-54.

17. Denham CR. SBAR for patients. J Patient Safe 2008;4:38-48.

18. Starmer AJ, Spector ND, Srivastava R, et al. I-PASS, a Mnemonic to Standardize Verbal Handoffs. Pediatrics 2012;129:201-4.

19. Farnan JM, Paro JaM, Rodriguez RM, et al. Hand-off education and evaluation: piloting the observed simulated hand-off experience (OSHE). J Gen Intern Med 2010;25:129-34.

20. Frank JR, Snell LS, ten Cate O, et al. Competency-based medical education: theory to practice. Med Teach 2010;32:638-45.

21. Ten Cate O, Snell L, Carraccio C. Medical competence: the interplay between individual ability and the health care environment. Med Teach 2010;32:669-75.

22. Englander R. Provide transfer of care that ensures seamless transitions. In: Carraccio C.ed The Pediatric Milestones Project. Chapel Hill, NC, USA: American Board of Pediatrics 2012:11-13.

23. Norcini JJ, Holmboe ES, Hawkins RE. Evaluation challenges in the era of outcomes-based education. In: Holmboe ES, Hawkins RE. eds. Practical guide to the evaluation of clinical competence. 1st edn. Philadelphia: Mosby Elsevier, 2008:1-9.

24. Foster S, Manser T. The effects of patient handoff characteristics on subsequent care: a systematic review and areas for future research. Acad Med 2012;87:1105-24.

25. Hesselink G, Schoonhoven L, Barach P, et al. Improving patient handovers from hospital to primary care. Ann Intern Med 2012;157:417-28. 